\title{
p53 expression in oat and non-oat small cell lung carcinomas: correlations with proliferating cell nuclear antigen
}

\author{
P Korkolopoulou, J Oates, J Crocker, C Edwards
}

\begin{abstract}
Aims-To investigate the immunohistochemical expression of $p 53$ protein in small cell lung carcinoma (SCLC), comparing it with that in non-small cell carcinoma (NSCLC); and to evaluate the correlation between p53 and proliferating cell nuclear antigen (PCNA) expression as well as between p53 and PCNA expression and survival.

Methods-Paraffin wax embedded tissues from 61 cases of primary lung carcinoma were stained for $p 53$ protein and PCNA using the monoclonal antibodies 1801 and PC-10, respectively, in a standard avidin-biotin immunoperoxidase method.
\end{abstract}

Results-Of the 61 lung carcinomas 35 (57\%) were positive for p53 (range $1 \%$ to $90 \%$ ). Ninety percent of the non-oat SCLC contained positive cells and the labelling index (LI) was significantly higher than that of the oat SCLC (p < 0.001). SLCC also displayed a higher p53 LI than NSCLC $(p<0.01)$; no difference was found between squamous carcinoma, adenocarcinoma, and oat cell carcinoma. A p53 LI of greater than $1 \%$ tended to be associated with nodal metastases $(p<0.05)$, and p53 expression in node positive tumours as well as in oat cell carcinomas was indicative of poorer survival $(p<0.01$ and $p<0.1$, respectively). A p53 $\mathrm{Li}$ of greater than $60 \%$ was a negative prognostic factor in non-oat SCLC $(p<0.05)$. PCNA LI was highest in non-oat SCLC and lowest in NSCLC; oat cell carcinomas had a mean LI intermediate between NSCLC and non-oat SCLC (NSCLC $v$ oat cell carcinoma $p<0.05$ and oat cell $v$ non-oat cell carcinomas $p<0.01$ ). A PCNA LI was not correlated with nodal metastases or survival, but there was a significant positive correlation between PCNA LI and p53 LI ( $\mathbf{r}_{\mathbf{s}}=0.484$, p $\left.<0.001\right)$.

Conclusions-p53 and PCNA expression differ substantially among the various types of lung carcinomas. Substantial differences were also found between oat and non-oat types of SCLC, indicating that SCLC is heterogeneous as far as proliferation rate and altered p53 expression is concerned. p53 seems to be of some prognostic value. The relation between PCNA and p53 expression indicates that the PCNA gene is slightly upregulated by $p 53$.

(F Clin Pathol 1993;46:1093-1096)

p53 protein is a nuclear phosphoprotein encoded by a gene located on the $17 \mathrm{P}$ chromosome. In in its wild form, it is regarded as a tumour suppressor gene whose inactivation is an almost universal step in the development of human malignancies. ${ }^{1}$ Wild p53 protein regulates cell proliferation by arresting the cell cycle in the G1 phase. ${ }^{2}$ It also acts as a "molecular policeman" by accumulating in response to DNA damage, and inhibiting proliferation while repair takes place. ${ }^{3}$ If repair fails p53 continues to accumulate until apoptosis occurs.

Inactivation of $\mathrm{p} 53$ leads to unrestrained cellular proliferation, genetic instability, and heightened susceptibility to malignant transformation. ${ }^{3}$ Inactivation may be the result of binding to host or viral protein, or may be caused by gene mutation. The abnormal protein encoded by the mutant p53 gene not only forms an inert hetero-oligomer with the wild type protein, but it is also more stable, and accumulates in the nucleus in sufficient quantities to be detected immunohistochemically. ${ }^{4}$ The immunohistochemical demonstration of p53 protein is therefore regarded as an indication of mutation in the p53 gene. Several neoplasms have been associated with altered p53 gene expression, including colorectal, ${ }^{5}$ breast carcinomas, ${ }^{6}$ as well as haematopoietic malignancies. ${ }^{1}$

Accumulating evidence indicates that lung cancer arises as a result of multiple genetic changes in dominant oncogenes such as ras and suppressor genes such as p53, often in the same tumour. ${ }^{7}$ Abnormal p53 expression has been convincingly demonstrated in lung carcinomas using molecular-11 and immunohistochemical techniques, ${ }^{42-14}$ but most of these studies have focused on squamous carcinomas and adenocarcinomas: the number of small cell carcinomas (SCLC) studied has been small.

\section{Methods}

This study was based on 61 cases of primary lung carcinoma taken from the files of the 


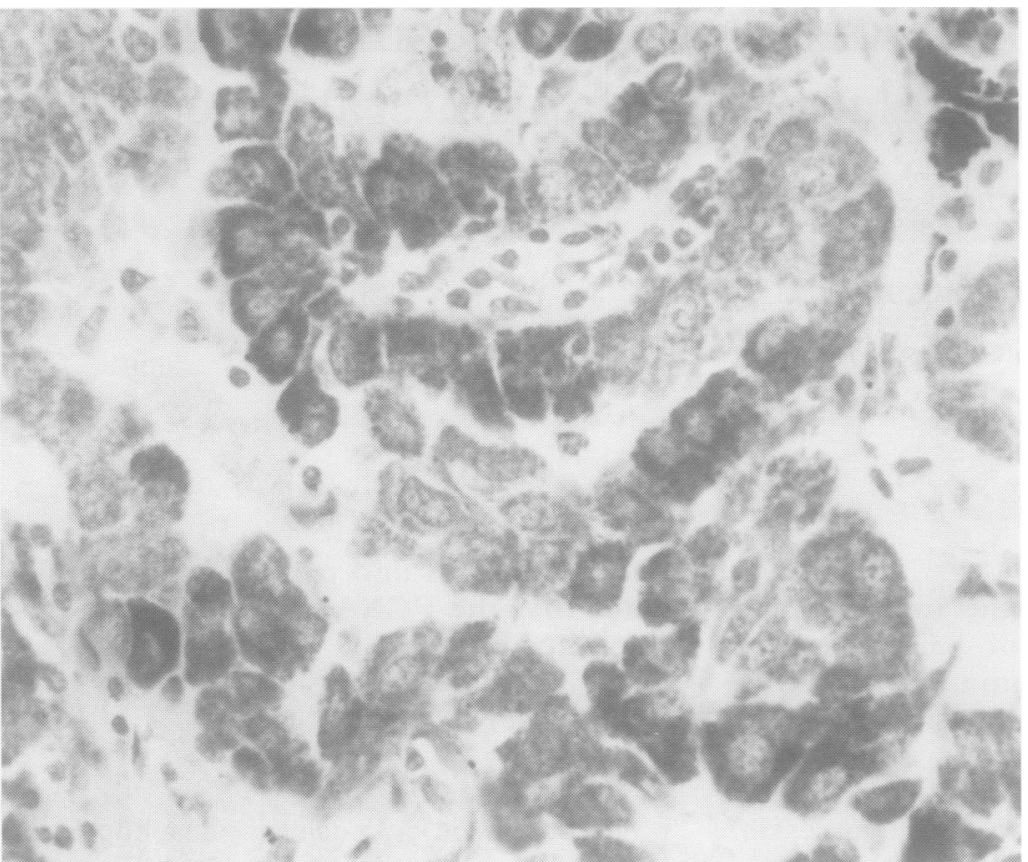

Figure 1 Adenocarcinoma showing positive cytoplasmic staining for $p 53$.

Table 1 p53 expression in lung carcinomas

\begin{tabular}{lcll}
\hline & $n=$ & $\begin{array}{l}\text { No of } \\
\text { positive cases }\end{array}$ & $\begin{array}{l}\text { p53 labelling index } \\
\text { (range and median value) }\end{array}$ \\
\hline Squamous carcinoma & 10 & 5 & $1 \cdot 5-65,15$ \\
Adenocarcinoma & 14 & 5 & $1-10,1$ \\
Adenosquamous carcinoma & 3 & 2 & $2-35$ \\
Oat cell SCLC & 13 & 4 & $10-70,12 \cdot 5$ \\
Non-oat cell SCLC & 21 & 19 & $5-90,40$ \\
Total & 61 & 35 & \\
\hline
\end{tabular}

Pathology Department of East Birmingham Hospital from 1977 to 1990 . Tumour tissue was obtained by open biopsy $(n=7)$ or surgical resection $(n=54)$. The histological diagnoses were reviewed by an experienced lung pathologist (CWE). Thirty four cases of SCLC consisting of 13 oat and 21 non-oat

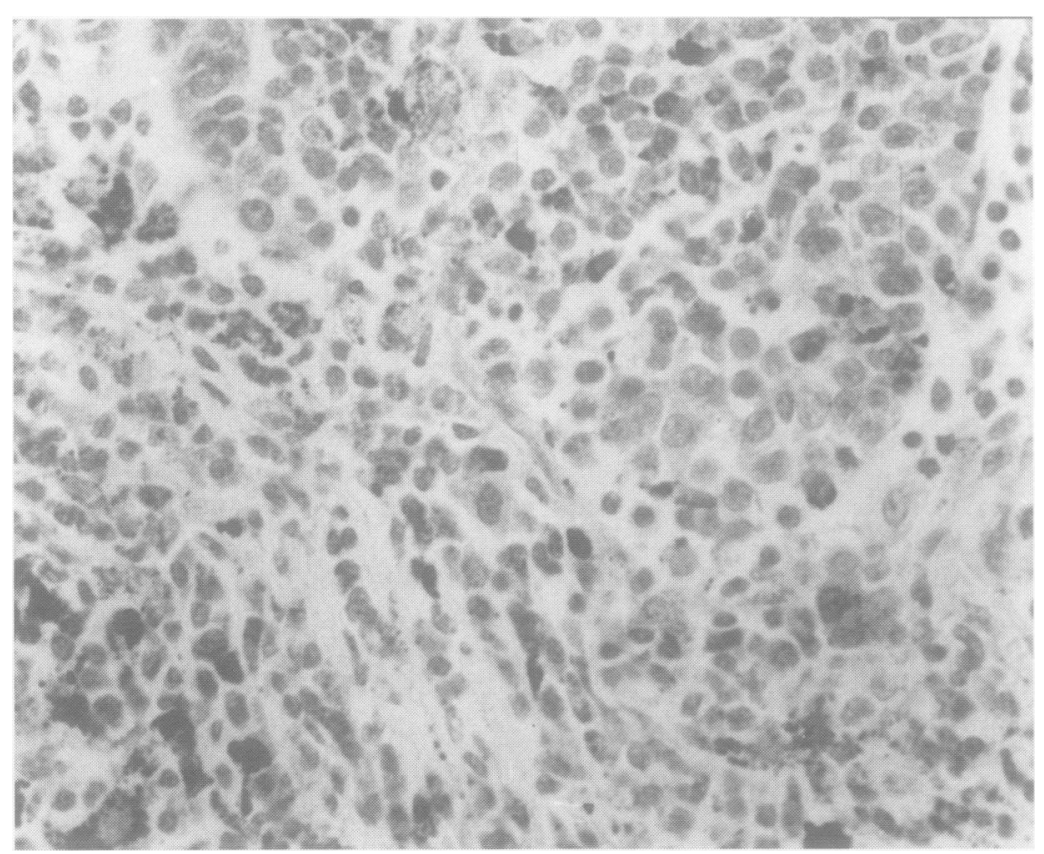

Figure 2 Oat cell SCLC showing only scanty positive nuclear staining for p53. A little cytoplasmic staining is also present. carcinomas and 27 cases of NSCLC (10 squamous, three adenosquamous, and 14 adenocarcinomas) were examined. Non-oat cell SCLC were defined as small cell carcinomas which did not fulfil the WHO diagnostic criteria for oat cell carcinomas. ${ }^{15}$ In the resection specimens the size of the tumour and nodal status were also recorded. Survival data from the Birmingham Cancer Registry were available for 40 cases.

All specimens had been fixed in $10 \%$ formalin and routinely processed for paraffin wax embedding. Sections were cut at $3 \mu \mathrm{m}$ and mounted on Vectabond treated glass slides. The slides were air dried at $37^{\circ} \mathrm{C}$ for at least 24 hours and then stained immunohistochemically for p53 protein using the monoclonal antibody PAB 1801 (Dr L Young) and for PCNA in 44 cases using the monoclonal antibody PC-10 (Dakopatts). For immunostaining the three-step avidin-biotin technique (Vecta-stain Elite PK6102) was used. The antibody 1801 was diluted 1 in 5 in phosphate buffered saline (PBS) (pH7.4). PC-10 was diluted 1 in 50 in PBS ( $\mathrm{pH} 7 \cdot 4)$. Incubation time was 30 minutes at room temperature for both antibodies.

Staining was assessed blind (without knowing the various clinicopathological parameters) and independently by two observers (CWE and PK). Positive non-neoplastic cells or cells showing only cytoplasmic staining were not taken into account. In each case nuclei from about 1000 tumour cells from 10 high power fields were counted and the labelling index (LI) was calculated as the percentage of positive neoplastic nuclei. Although the intensity of staining varied, all identifiable nuclear staining was recorded as positive. In cases with patchy staining areas containing the highest and lowest number of positive cells were selected and the percentages were averaged to give the $\mathrm{LI}$.

The results were statistically evaluated using Student's $t$ test, Wilcoxon's rank sum test, the $\chi^{2}$ test and Spearman's rank correlation coefficient. Survival data were analysed using the log-rank test.

\section{Results}

Of the 61 tumours studied, $35(57 \%)$ gave a positive nuclear reaction for $\mathrm{p} 53$. The distribution of positive nuclei was patchy in many cases, but they were always seen in tumour cells and never in normal tissue. In one squamous carcinoma positivity was confined to the in situ component. In 12 cases one squamous carcinoma, five adenocarcinomas, one adenosquamous carcinoma and five SCLC) some cytoplasmic staining was also evident (fig 1).

p53 expression varied according to histological type. Positive nuclei were found in $30 \%$ of oat cell SCLC, $36 \%$ of adenocarcinomas, and $50 \%$ of squamous carcinomas compared with $90 \%$ of non-oat SCLC (table 1) (figs 2 and 3). The p53 LI of the small cell group as a whole was significantly higher than that of the non-small cell tumours $(p<0.01)$. 


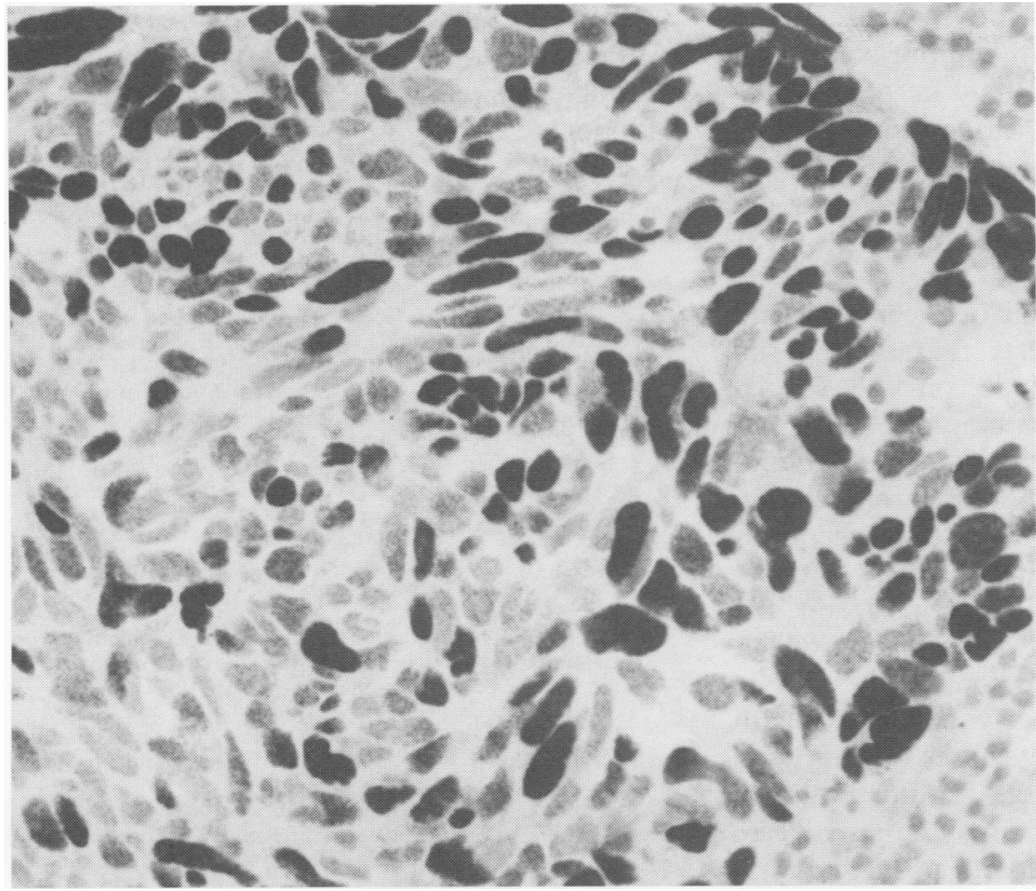

Figure 3 Non-oat cell SCLC with extensive positive nuclear staining for p53. No cytoplasmic staining is present.

More importantly, the non-oat SCLC had a significantly higher p53 LI than the oat cell tumours $(\mathrm{p}<0.0001)$.

p53 expression was also related to prognosis and survival. In general, a p53 LI of greater than $1 \%$ tended to be associated with nodal metastases $(p<0.05)$, and in patients with nodal metastases there was a significant correlation between p53 LI and survival (p < $0 \cdot 01$ ). In the oat cell group any p53 expression of whatever intensity implied a poor prognosis $(p<0.01)$; in the non-oat SCLC group it was the subjects with a p53 LI of

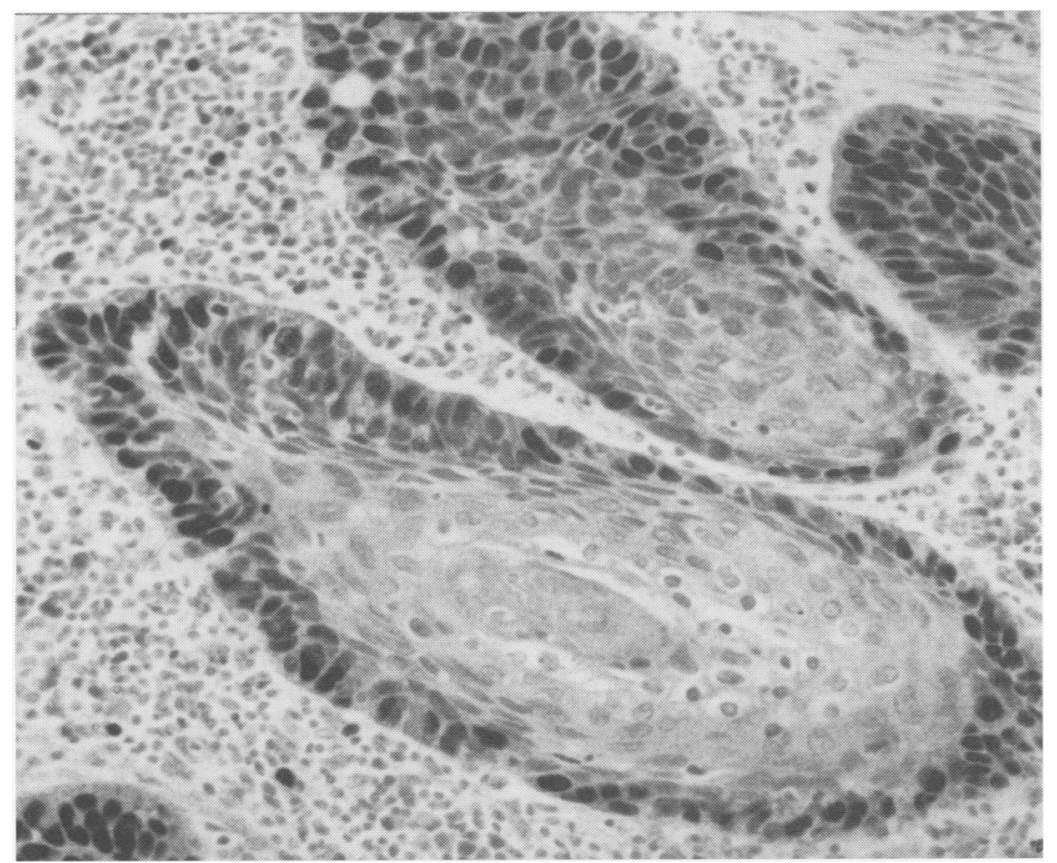

Figure 4 Squamous cell carcinoma showing nuclear staining for PCNA at the periphery of the tumour islands.
Table $2 \quad P C N A$ index in lung carcinomas

\begin{tabular}{lrl}
\hline & $n=$ & $\begin{array}{l}\text { PCNA labelling index (\%) } \\
\text { Mean (SD) }\end{array}$ \\
\hline Squamous carcinoma & 9 & $43 \cdot 3(23 \cdot 3)$ \\
Adenocarcinoma & 10 & $25 \cdot 2(18 \cdot 8)$ \\
Adenosquamous carcinoma & 2 & $47 \cdot 5(3 \cdot 5)$ \\
Oat cell SCLC & 10 & $56 \cdot 5(21 \cdot 7)$ \\
Non-oat cell SCLC & 15 & $78 \cdot 3(11 \cdot 0)$ \\
\hline
\end{tabular}

over $60 \%$ who fared worse than the rest $(\mathrm{p}<$ $0.05)$. Although a p53 LI of greater than $5 \%$ was more often associated with short survival, a significant correlation was not achieved. There was no correlation between p53 LI and tumour size.

PCNA immunoreactivity was shown in all cases, and was mostly nuclear, although cells in mitosis showed cytoplasmic staining. Cell nuclei in normal lung tissue were negative. The distribution of positive nuclei was homogeneous in some cases, while in others there was considerable field to field variation. In squamous carcinoma staining was most intense in the periphery of the tumour islands (fig 4); in two tumours the keratinising cells showed weak cytoplasmic positivity.

The mean proliferative indices in the various groups of tumours are shown in table 2. The PCNA LI ranged from $10 \%$ to $95 \%$. SCLC had a significantly higher mean PCNA LI than NSCLC ( $p<0.0001)$, and the mean PCNA LIs of the oat and non-oat SCLC also differed significantly $(p<0.01)$. A significant positive correlation between the PCNA LI and p53 LI $\left(r_{s}=0.484 ; p<0.001\right)$ was also found. There was no correlation between PCNA LI and tumour size, nodal status, or survival.

\section{Discussion}

This study confirms previous reports that a significant proportion of primary lung carcinomas express the mutant p53 protein. ${ }^{4-14}$ It also confirms the results of other investigations into p53 expression with various histological types of NSCLC, ${ }^{131416}$ while contradicting, to some extent, the findings of Iggo et $a l^{4}{ }^{4}$ who reported a high level of p53 expression in squamous carcinomas. Different antibodies were used in this latter study, however.

The most important point to emerge from our investigation is that expression of p53 in non-oat cell SCLC is higher than in other histological types. Furthermore, the increased p53 expression in this group is paralleled by an increase in PCNA expression, ${ }^{17}$ and there is a gradient of PCNA Ll from adenocarcinomas through squamous carcinomas and oat SCLC to non-oat SCLC.

A low level of PCNA expression in adenocarcinomas compared with squamous carcinomas was reported by Carey et al, ${ }^{18}$ but as far as we are aware, findings similar to ours have not been recorded before, although Barbareschi et al ${ }^{12}$ showed that a decrease in neuroendocrine features is associated with an 
increase in proliferative activity and altered expression of tumour suppressor gene products. These findings may be of diagnostic relevance in that lung carcinomas displaying a p53 LI of greater than or equal to $20 \%$, and a PCNA LI of greater than $50 \%$ are more likely to belong to the non-oat SCLC group.

The positive correlation between p53 and PCNA expression suggests that there is an up-regulating effect of p53 on the PCNA gene in primary lung carcinomas. In other tumours, such as central nervous system neoplasms ${ }^{19}$ and breast carcinomas, ${ }^{20}$ this relation does not exist. Reported data, however, indicate that mutant p53 may directly activate PCNA promoter ${ }^{21}$ : wild type p53, on the other hand, selectively deregulates PCNA mRNA and protein expression. ${ }^{22}$

p53 expression positively correlated with the presence of nodal metastases but not with tumour size. A remarkable finding is that a p53 LI of greater than $5 \%$ may be an adverse prognostic factor in cases with positive lymph nodes; it is of no relevance when there is no lymph node metastasis. Prognostically significant p53 expression was also found in oat as well as in non-oat SCLC. These results should, however, be interpreted with caution because there are well known associations between histological type, lymph node status, and prognosis in lung carcinomas. Furthermore, data concerning the prognostic utility of altered p53 expression in lung carcinomas are sparse and contradictory. Quinlan et $a l^{23}$ showed a negative prognostic value of p53 LI in adenocarcinomas and squamous carcinomas while Hiyoshi $e t a l^{14}$ found that accumulation of $\mathrm{p} 53$ protein is of prognostic value only in adenocarcinomas. Chiba $e t a l^{11}$ failed to demonstrate any relation between the presence of p53 mutations and tumour stage or nodal status in NSCLC. PCNA, on the other hand, does not generally correlate with nodal metastases or prognosis, although Fontanini et $a l^{24}$ showed that PCNA immunostaining is of prognostic value in resected peripheral, node negative NSCLC.

In a recent study a note of caution was sounded regarding intratumoural heterogeneity of expression of proliferation markers, particularly PCNA. ${ }^{18}$ Because this investigation used archival surgical material, the number of available blocks of tumour tissue was limited to three for each case at the most. The problem of heterogeneity was addressed by selecting areas containing the highest and lowest proportions of positive nuclei, and averaging the counts to obtain the $\mathrm{LI}$. In clinical practice, however, dealing with individual cases, more systematic sampling, and counting will be required: a minimum of five blocks of tumour has been advocated. ${ }^{18}$

In conclusion, p53 and PCNA expression differ substantially among the various types of lung carcinoma, being highest in non-oat SCLC which seem to represent a group distinct from oat SCLC. p53 expression also seems to be of some prognostic value, although clinical studies in a larger series of patients are required.

We are grateful to Mrs Ruth Fry for her secretarial assistance, and to Dr L Young, Cancer Studies, University of Birmingham, for providing antibody PAB 1801 .

1 Hollstein M, Sidransky D, Vogelstein B, Harris C. p53 mutations in human cancers. Science 1991;253:49-53.

2 Milner JH. The role of $p 53$ in normal control of cell proliferation. Curr Op Cell Biol 1991;3:282-6.

3 Lane DP. p53, guardian of the genome. Nature 1992; 358:15-6.

4 Iggo R, Gatter K, Bartek J, Lane D, Harris AL. Increased expression of mutant forms of $\mathrm{p} 53$ oncogene in primary lung cancer. Lancet 1990;335:675-9.

5 Purdie CA, O'Grady J, Piris J, Wyllie AH, Bird CC. p53 expression in colorectal tumours. Am $\mathcal{F}$ Pathol 1991; 138:807-13.

6 Prosser S, Thompson AM, Cranston G, Evans JH. Evidence that $\mathrm{p} 53$ behaves as a tumor suppressor gene in sporadic breast tumors. Oncogene 1990;5:1573-9.

7 Takahashi T, Carbone D, Takahashi T, et al. Wild-type but not mutant p53 suppresses the growth of human lung cancer cells bearing multiple genetic lesions. Cancer Res 1992;52:2340-3.

8 Kishimoto Y, Murakami Y, Shiraishi M, Hayashi K, Sekiya T. Aberrations of the p53 tumor suppressor gene in human non-small cell carcinomas of the lung. Cancer Res 1992;52:4799-804.

9 Kondo K, Umemoto A, Akimoto S, et al. Mutations in the p53 tumour suppressor gene in primary lung cancer in

10 D'Amico D, Carbone D, Milsudami T, et al. High frequency of somatically acquired p53 mutations in smallcell lung cancer cell lines and tumors. Oncogene 1992; 7:339-46.

11 Chiba I, Takahashi T, Nau MM, et al. Mutations in the p53 gene are frequent in primary resected non-small cell lung cancer. Lung Cancer Study Group. Oncogene 1990;5:1603-10.

12 Barbareschi M, Girlando S, Mauri FA, et al. Tumour suppressor gene products, proliferation and differentiation markers in lung neuroendocrine neoplasms. $₹$ Pathol 1992;166:343-50.

13 Volm M, Efferth T, Mattern J. Oncoprotein (c-myc, cerbB1, c-erbB2, c-fos) and suppressor gene product (p53) expression in squamous cell carcinomas of the lung. Clinical and biological correlations. Anticancer Res 1992;12:11-20.

14 Hiyoshi H, Malsuno Y, Kato H, Shimosato Y, Hirohash S. Clinicopathological significance of nuclear accumulation of tumor suppressor gene $p 53$ product in primary lung cancer. $\mathcal{F p}_{p} \mathcal{F}$ Cancer Res 1992;83:101-6.

15 World Health Organization. International Histological Classification of Tumours. Histological typing of lung tumours. 2nd edn. Geneva: World Health Organization, 1981.

16 Caamano J, Ruggeri B, Momiki S, Sickler A, Zhang SY, Klein-Szanto AJ. Detection of p53 in primary lung tumors and non-small cell lung carcinoma cell lines. $\mathrm{Am}$ f Pathol 1991;139:839-45.

17 Hall PA, Levison DA, Woods AL, et al. Proliferating cell nuclear antigen (PCNA) immunolocalisation in paraffin sections: An index of cell proliferation with evidence of deregulated expression in some neoplasms. $\mathcal{F}$ Pathol 1990;162:285-94

18 Carey FA, Fabbroni G, Lamb D. Expression of proliferating cell nuclear antigen in lung cancer; a systemic study and correlation

19 Barbareschi $M$, Iuzzolino $P$, Pennella A, et al. p53 protein expression in central nervous system neoplasms. $\mathcal{f}$ Clin Pathol 1992;45:583-6.

20 Leonardi E, Girlando S, Mauri FA, Dalla Palma P, Barbareschi M. PCNA and Ki67 expression in breas carcinoma. Correlations with clinical and biological variables. ₹ Clin Pathol 1992;45:416-9.

21 Deb S, Jackson CT, Subler MA, Martin DW. Modulation of cellular and viral promotors by mutant human p53 proteins found in tumor cells. 7 Virol 1992;66:6164-70.

22 proteins WE Shields MT Lin D Appla E, Ullich SI. Growth suppression induced by wild-type p53 protein is accompanied by selective down-regulation of proliferating cell nuclear antigen expression. Proc Natl Acad Sci ing cell nuclear antigen

23 Quinlan DC, Davidson AG, Summers CL, Warden HE, Doshi HM. Accumulation of p53 protein correlates with a poor prognosis in human lung cancer. Cancer Res 992;52:4828-31.

24 Fontanini G, Macchiarini P, Pepe S. The expression of proliferating cell nuclear antigen in paraffin sections of peripheral node-negative non-small cell lung cancer. Cancer 1992;70:1520-7. 